\title{
De la vieillesse et des «vieux magnifiques»
}

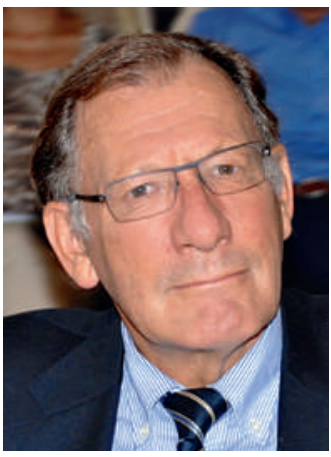

Jean Martin
Curaviva, association des homes et institutions sociales suisses, tenait à Lausanne en février son «Congrès Personnes âgées» biennal, destiné aux responsables et collaborateurs d'EMS. Riche programme avec une palette de conférenciers d'horizons divers. Ainsi le philosophe allemand Wilhelm Schmid qui a fait l'éloge du temps long, opposant la culture des cycles (naturels notamment) et de l'espace, qui prend le temps de la réflexion et du loisir (avec ses «Goldene Stunden»), et la culture linéaire moderne, poussant constamment vers plus et plus vite. Avec la personnalité berlinoise des média Bascha Mika: philippique féministe radicale et drôle, renvoyant à leurs erreurs et insuffisances respectives les mâles vaniteux et manquant de sensibilité et les femmes qui continuent à rêver prioritairement de bonheur domestique en se pliant à l'ordre décrété par les hommes. Affirmant aussi (il y a là une part de vérité) que la vieillesse est une notion «construite» (comme Simone de Beauvoir puis les féministes parlent du sexe/genre), quelque chose que les sociétés formatent. Evident par exemple quand on compare le respect et l'autorité accordés, ou pas, aux anciens dans différents contextes.

Age et/vs. vieillesse. Un propos qui a retenu l'attention est celui du philosophe français André ComteSponville, un des intellectuels de la République voisine dont les ouvrages sur les grandes questions (de l'époque et de toujours) sont bien accessibles. Sous le titre «Que philosopher, c'est apprendre à vieillir» en paraphrasant Montaigne, il a mis en évidence la différence entre l'âge, notion objective de nos cartes d'identité, extérieure en quelque sorte, et la vieillesse, qualitative, intérieure, vécue si différemment par les uns ou les autres.

Citant des formules qui disent bien ce qu'elles veulent dire. On ne se sent guère vieillir: «Le drame quand on est vieux, c'est qu'on croit être resté jeune.» «Vieillir, c'est rencontrer de plus en plus souvent des gens plus jeunes que soi.» Si juste - ma sensation en participant audit congrès. Il a fustigé un certain politiquement correct quant aux termes. «Dire vieux ou vieillard, ce n'est pas comme le racisme ou l'homophobie», c'est dire vrai. Pourquoi les remplacer par senior ou tel autre terme? Ne pas les écarter, ne serait-ce pas confirmer une certaine dignité à l'âge avancé?

Les «vieux magnifiques». Le journaliste Jacques Pilet a donné ce terme, soulignant ce que les anciens peuvent apporter - l'expérience est la seule chose qui ne s'apprend pas dans les livres. En nommant deux tendances qu'il faut refuser: la nostalgie du passé («l'âge d'orisme» est un poison!) et le refus par les âgés de se mettre aux technologies nouvelles. Pilet et Comte-Sponville ont ainsi évoqué quelques intellectuels encore remarquablement actifs, incisifs, précieux pour la société: Stéphane Hessel, Edgar Morin, Jean d'Ormesson, l'acteur Michel Bouquet.

Bien vieillir demande un travail sur soi-même, c'est l'évidence. Apprendre à s'intéresser (mieux) aux autres. Nombre d'entre nous peuvent se sentir concernés après avoir, durant leur vie dite active, voulu trop faire et trop vite.

Apprendre à vivre au présent, ce qui ne veut pas dire vivre dans l'instant. Vivre au présent c'est profiter de manière aussi complète que possible de ce qui est vécu sur le moment, sans négliger le passé et s'amputer de sa mémoire, partie majeure de ce que nous sommes, mais sans s'appesantir sur ce qui n'a pas été optimal. Il ne s'agit pas non plus de négliger l'avenir et ce qui pourra advenir, mais sans en être obsédé: à trop nous préoccuper du futur, «nous ne vivons jamais» (Pascal). Comte-Sponville voudrait aider les gens à philosopher tant qu'ils peuvent et à faire de leur vieillesse une occasion de bonheur continué.

La mort a aussi été évoquée, bien sûr. Citant cet enseignant disant à ses étudiants incertains de réussir un examen: «Le seul examen que personne n'ait jamais raté, c'est la mort.»

S'attacher à aimer la vie plutôt que craindre la mort (en accepter l'idée). NB: un auteur classique engageait ses auditeurs à ne pas en avoir peur: «Ma mort et moi, nous ne nous rencontrerons jamais; si je suis présent elle n'y est pas, et vice versa. Par contre, ma vieillesse et moi, on se rencontre et on doit vivre ensemble.»

Pour ceux qui sont confrontés à une perte douloureuse comme celle d'un conjoint ou proche, Comte-Sponville propose de développer sa capacité de gratitude plutôt que de regret. Penser/dire: «Comme c'est bien qu'il/elle ait existé», plutôt que «Comme c'est triste qu'il/elle ne soit plus.» Que je rapproche de cette phrase entendue récemment lors d'un service funèbre «Tu peux pleurer, te refermer, être vide et tourner le dos, ou tu peux faire ce qu'elle aurait voulu, ouvrir les yeux, aimer et aller de l'avant.»

Jean Martin, membre de la rédaction et de la Commission nationale d'éthique 